\title{
The proportion of death anxiety and its related factors during the COVID-19 pandemic in the Iranian population
}

\author{
SEYEDMOHAMMAD MIRHOSSEINI', A, B, E, F, ALI DADGARI 2, A, E, F, \\ ORCID ID: 0000-0002-2087-0164 \\ ORCID ID: 0000-0003-1836-8236 \\ MOHAMMAD HASAN BASIRINEZHAD ${ }^{3, C-E}$, REZA MOHAMMADPOURHODKI ${ }^{4, \mathrm{~B}, \mathrm{E}, \mathrm{F}}$, \\ HOSSEIN EBRAHIMI ${ }^{5, A}, B, E, F$ \\ ORCID ID: 0000-0001-5731-7103
}
${ }^{1}$ Student Research Committee, School of Nursing and Midwifery, Mashhad University of Medical Sciences, Mashhad, Iran
${ }^{2}$ Department of Nursing, School of Nursing and Midwifery, Shahroud University of Medical Sciences, Shahroud, Iran
${ }^{3}$ Department of Epidemiology and Biostatistics, School of Public Health, Tehran University of Medical Sciences,
Tehran, Iran
${ }^{4}$ Kashmar Center of Higher Health Education, Mashhad University of Medical Sciences, Mashhad, Iran
${ }^{5}$ Center for Health Related Social and Behavioral Sciences Research, Shahroud University of Medical Sciences, Shahroud, Iran

A - Study Design, B - Data Collection, C - Statistical Analysis, D - Data Interpretation, E - Manuscript Preparation, F - Literature Search, G - Funds Collection

Summary Background. The worldwide emergence of COVID-19 has brought about various psychological consequences, including anxiety, fear of death, etc.

Objectives. This study was aimed at determining the proportion of death anxiety and its covariates during the COVID-19 pandemic in Shahroud city, Iran.

Material and methods. This cross-sectional study was conducted on 1,215 participants. Data was collected by convenient sampling method with online tools, including an awareness and attitude checklist toward COVID-19, Templar Death Anxiety Questionnaire and the Generalized Anxiety Disorder (GAD-7) Questionnaire. The data was analyzed using descriptive and inferential statistics (multivariate linear regression analysis). The significant level for all tests was considered to be 0.05 .

Results. The results indicated that the mean score \pm standard deviation of death anxiety and GAD were $6.46 \pm 3.33$ and $6.27 \pm 4.83$, respectively. Of all participants, $49.1 \%$ reported high death anxiety. Parallel to the high anxiety level, a significant increase in death anxiety was observed $(p<0.001)$. Moreover, factors such as younger age and the death of a family member due to COVID-19 were significantly correlated with death anxiety $(p=0.024$ and $p=0.001)$.

Conclusions. Assessing anxiety among exposed clients and applying anxiety reduction and coping methods, such as problem-solving techniques, as well as providing comprehensive and practical information on methods to control and adapt with this disease, are recommended to be implemented in health care systems.

Key words: anxiety, coronavirus, death, mental health, pandemics.

Mirhosseini S, Dadgari A, Basirinezhad MH, Mohammadpourhodki R, Ebrahimi H. The proportion of death anxiety and its related factors during the COVID-19 pandemic in the Iranian population. Fam Med Prim Care Rev 2021; 23(1): 36-40, doi: https://doi.org/10.5114/ fmpcr.2021.103154.

\section{Background}

The COVID-19 outbreak not only carries the risk of death but also has imposed a severe psychological burden on community dwellers around the world [1]. In addition, it brings about various other health issues, such as stress, anxiety and depression [2]. For a variety of reasons, including being in collective quarantine, infodemic on COVID-19, ongoing reports of increased mortality and the contiguous nature of the disease, some levels of anxiety are reported among all communities [3].

There is growing literature emphasizing the significant psychological impact of the recent COVID-19 outbreak [4]. In this regard, people encountering stressful events, such a life-threatening diseases, would experience death anxiety [5]. Similarly, the results of studies showed that fear of death is directly related to some anxiety disorders, such as obsessive-compulsive disorder, Generalized Anxiety Disorder (GAD), social anxiety and panic disorder [6]. During the COVID-19 outbreak, community dwellers in China reported a psychological effect. Results showed that participants of the study reported symptoms of depression (16.5\%), anxiety (28.8\%) and moderate to severe stress symptoms (8.1\%) [7]. In addition, in a study in China investigating the rate of GAD, depression and sleep quality during the COVID-19 outbreak showed that the prevalence of these issues was $35.1,20.1$ and $18.2 \%$, respectively [8].

The Australian government has emphasized the psychological side effects of COVID-19 and expressed concern about its long-term effects on isolation [9]. They highlighted the influential effects of being exposed to fake or real news during the outbreak. Results of a previous study showed that more than $80 \%$ of the participants were using social media, $48 \%$ had depressive symptoms, and $22 \%$ had anxiety symptoms [10]. Moreover, those participants exposed to news, media and social networks reported more anxiety and depression. 
This study is based on the Terror Management Theory (TMT) and the concept of death anxiety. The TMT postulates that psychological needs are primarily rooted in existential dilemmas [11]. Human beings have an internal desire for existence and creating opportunities for survival and longevity [12]. In addition, they are equipped with intellectual abilities making them aware of death [11]. The imminent risk of losing one's life can also serve as a trigger for the occurrence of changes in the meaning of one's existence, such as intensification of beliefs and strengthening of social and relationship bonds [13]. The instinctual awareness of terror and death exposes them to emotional reactions [14], such as anxiety. COVID-19 and its complications on different aspects of life in communities are a growing public health concern worldwide. Much uncertainty still exists about the relationship between the COVID-19 outbreak and death anxiety among community dwellers. Therefore, it is necessary to examine the various dimensions of death anxiety and its covariates.

\section{Objectives}

The current study was aimed at determining the association of death anxiety and its covariates to the COVID-19 pandemic among Iranian community dwellers.

\section{Material and methods}

\section{Study design}

This study is a quantitative study with a cross-sectional approach.

\section{Setting}

In this study was conducted through cyberspace among community dwellers. Online questionnaires were used to safely access participants in order to prevent them from the spread of disease.

\section{Participants}

The participants of the current study were community dwellers living in Shahroud city, Semnan Province, Iran. Inclusion criteria were the ability to read and write, access to the Internet and the ability to apply mass media in cyberspace to complete the questionnaires. By sending the invitation to participate in the study, they were informed of the terms and conditions of this research. Furthermore, they had to fill in both an informed consent form and the online questionnaire page.

\section{Variables}

The current study applied three variables, including (a) independent variables, which include demographic characteristics (age, gender, level of education, marital status, job status, place of residence, hours of follow-up for COVID-19 news and assessment of immediate and extended relatives concerning death and infectious history due to COVID-19) and awareness and attitude toward COVID-19, as well as (b) death anxiety score and (c) generalized anxiety score.

\section{Data sources/measurement}

The participants of the study were asked to fill in the demographic profile and questions in three questionnaires of Awareness and Attitude Assessment Checklist for COVID-19, Templar Death Anxiety Scale (TDAS) and Spitzer's Generalized Anxiety Disorder (GAD-7) in a self-reported manner.

Level of awareness and attitude toward COVID-19 disease was assessed by a checklist consisting of 6 questions. 1 - Inhaling droplets from sneezing, coughing or conversation with an infected person can spread the virus. 2 - Physical contact with objects contaminated by an infected person can cause infection. 3 - The incubation period of the coronavirus would not exceed 14 days. 4 - Contact with an asymptomatic person may also lead to the transmission of the coronavirus. 5 - At present, there are approved medications that can treat COVID-1. 6 - Drinking of warm fluids can prevent this disease. The correct answer to each one of the questions got one point. A total score of 5 or more indicates complete awareness; scores of 3 or 4 indicate relative awareness, and scores less than 3 show unawareness of coronavirus [8]. The content and face validity of the checklist were approved by 10 faculty members of Shahroud University of Medical Sciences.

The Templar Death Anxiety Scale (TDAS) consists of fifteen questions with yes/no answers. Replying yes would obtain a score of 1 , and selecting no results in a score of zero; thus, the lowest and highest scores collected from each responder would be between 0 and 14 [15]. The Persian version of TDAS has been validated by Iranian researchers. Cronbach's alpha coefficients for the three factors were reported to be $68 \%, 49 \%$, and $60 \%$, respectively [16]. Templer reported a reliability coefficient of 83\% using the test-retest method [15].

The GAD-7 questionnaire consists of 7 questions with a score range of 0 to 21. Each option can result in 0 for "never", 1 for "some days", 2 for "more than half of the days" and 3 for "almost every day". The higher the score on this questionnaire, the more anxiety experienced by the participants. The questionnaire has a cut-off point, with a score of 10 indicating GAD in a client. The validity of the original version of the structural questionnaire was confirmed by analysis of covariance between this scale and the 20-item General Health Questionnaire (SF-20). Cronbach's alpha of the total instrument was calculated as 0.92 , and the test reliability coefficient was 0.83 in a two-week interval test-retest method. Convergent validity was assessed by comparing the correlation with the Beck anxiety questionnaire and was reported to be 0.72 . Moreover, the SCL-90 was reported to be 0.74 [17]. Cronbach's alpha for internal consistency of the Iranian version of this questionnaire was calculated as 0.85 . The correlation of the split-half method between two halves of the test was calculated to be 0.65 . The reliability of the questionnaire using the test-retest method was calculated as 0.48 for two-week intervals. The concurrent validity of the questionnaire with the Spielberger mode anxiety scale, Spielberger adjective anxiety and SCL-90 anxiety subscale were $0.71,0.52$ and 0.63 , respectively [18].

\section{Study size}

Based on the convenient sampling method, 1,247 participants completed the questionnaires in full. Of all participants, 1,215 responders were verified to have replied to the questionnaire, and the other 23 responses were excluded from the study due to repeated entry.

\section{Statistical methods}

The data was analyzed using descriptive statistics (mean and standard deviation for quantitative and chi-square data, frequency and percentage for qualitative data) and the inferential statistics test (multivariate linear regression analysis). The significant level for all tests was considered to be 0.05 .

\section{Ethical considerations}

The present study was approved by Shahroud University of Medical Sciences under Ethics Committee code IR. SHMU. REC.1398.177.

\section{Results}

The finding of the current study showed that $52.9 \%$ of the participants were male, and $64 \%$ were married. The participants 


\begin{tabular}{|c|c|c|}
\hline Parameters & Mean \pm SD & $n(\%)$ \\
\hline Age (years) & $33.70 \pm 10.69$ & \\
\hline Gender & $\begin{array}{l}\text { female } \\
\text { male }\end{array}$ & $\begin{array}{l}572(47.1) \\
643(52.9)\end{array}$ \\
\hline Marital status & $\begin{array}{l}\text { married } \\
\text { single }\end{array}$ & $\begin{array}{l}777(64.0) \\
438(36.0) \\
\end{array}$ \\
\hline Residence & $\begin{array}{l}\text { rural } \\
\text { urban }\end{array}$ & $\begin{array}{l}52(4.3) \\
1163(95.7)\end{array}$ \\
\hline Job & $\begin{array}{l}\text { self-employed, retired } \\
\text { health professional (physician, nurse, medical student, etc.) } \\
\text { employees of government agencies, municipalities, banks and others } \\
\text { teachers and students }\end{array}$ & $\begin{array}{l}515(42.4) \\
212(17.4) \\
264(21.7) \\
224(18.4)\end{array}$ \\
\hline $\begin{array}{l}\text { COVID-19 infection in first or second degree } \\
\text { relatives }\end{array}$ & $\begin{array}{l}\text { yes } \\
\text { no }\end{array}$ & $\begin{array}{l}217(18.6) \\
949(81.4) \\
\end{array}$ \\
\hline Death of relatives due to COVID-19 & $\begin{array}{l}\text { yes } \\
\text { no }\end{array}$ & $\begin{array}{l}60(5.1) \\
1106(94.9)\end{array}$ \\
\hline \multirow[t]{2}{*}{ Attitude and knowledge toward COVID-19 } & $\begin{array}{l}\text { lack of knowledge } \\
\text { general knowledge } \\
\text { quite knowledge }\end{array}$ & $\begin{array}{l}15(1.2) \\
417(34.3) \\
783(64.4)\end{array}$ \\
\hline & Mean \pm SD & \\
\hline Follow COVID-19 news (hours/day) & $2.22 \pm 1.73$ & \\
\hline
\end{tabular}

$N$ - number, GAD - generalized anxiety disorder, \% - percent, SD - standard deviation.

who reported that their immediate and extended relatives have been infected with or died from the COVID-19 virus were 217 (18.6\%) and $60(5.1 \%)$, respectively. The average daily time spent on following news on COVID-19 was $1.73 \pm 2.22$ hours. $64.4 \%$ of the participants were fully aware of COVID-19. Detailed findings of the study are summarized in Table 1.

According to the results of the present study, almost half of the participants (49.1\%) reported high death anxiety, and 253 (20.8\%) subjects reported high anxiety (Table 2 ).

The chi-square test found that the proportion of low death anxiety was significantly higher in men $(p=0.014)$. There was no significant relationship between participants' death anxiety and other demographic characteristics (Table 3).

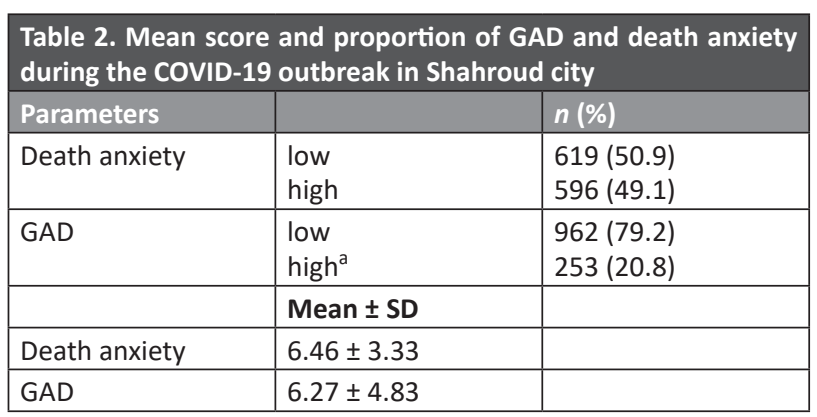

$N$ - number, GAD - generalized anxiety disorder, $\%$ - percent, SD - standard deviation, ${ }^{a}$ GAD was defined as individuals who scored $\geq 10$ points.

\begin{tabular}{|c|c|c|c|c|}
\hline \multirow{2}{*}{\multicolumn{2}{|c|}{ Parameters }} & \multirow{2}{*}{\multicolumn{2}{|c|}{ Death anxiety }} & \multirow{3}{*}{\begin{tabular}{|l|l|l}
$p$ \\
0.014
\end{tabular}} \\
\hline & & & & \\
\hline Gender & $\begin{array}{l}\text { female } \\
\text { male }\end{array}$ & \begin{tabular}{|l|} 
Low \\
$n(\%)$ \\
$270(43.6)$ \\
$349(56.4)$ \\
\end{tabular} & \begin{tabular}{|l|} 
High \\
$n(\%)$ \\
$302(50.7)$ \\
$294(49.3)$ \\
\end{tabular} & \\
\hline Marital status & $\begin{array}{l}\text { married } \\
\text { single }\end{array}$ & \begin{tabular}{|l|l|}
$395(63.8)$ \\
$224(36.2)$ \\
\end{tabular} & \begin{tabular}{|l|}
$382(64.1)$ \\
$214(35.9)$ \\
\end{tabular} & 0.919 \\
\hline Job & $\begin{array}{l}\text { self-employed, retired } \\
\text { health staff (physician, nurse, medical student, etc.) } \\
\text { employees of government agencies, municipalities, banks and others } \\
\text { teachers and students }\end{array}$ & $\begin{array}{l}249(40.2) \\
112(18.1) \\
142(22.9) \\
116(18.7) \\
\end{array}$ & $\begin{array}{l}266(44.6) \\
100(16.8) \\
122(20.5) \\
108(18.1) \\
\end{array}$ & 0.457 \\
\hline Residence & \begin{tabular}{|l|l|} 
rural \\
urban
\end{tabular} & \begin{tabular}{|l|l|}
$26(4.2)$ \\
$593(95.8)$ \\
\end{tabular} & \begin{tabular}{|l|}
$26(4.4)$ \\
$570(95.6)$ \\
\end{tabular} & 0.889 \\
\hline $\begin{array}{l}\text { COVID-19 infection in first } \\
\text { or second degree relatives }\end{array}$ & $\begin{array}{l}\text { yes } \\
\text { no }\end{array}$ & $\begin{array}{l}102(17.3) \\
489(82.7)\end{array}$ & $\begin{array}{l}115(20.0) \\
460(80.0)\end{array}$ & 0.229 \\
\hline
\end{tabular}

$N$ - number, $\%$ - percent, $p-p$-value.

Table 4. Role of independent parameters on death anxiety of the study participants in the multivariate linear regression model

\begin{tabular}{|l|l|l|l|l|}
\hline Parameters & $\boldsymbol{B}$ & SE & $\boldsymbol{t}$ & $\boldsymbol{p}$ \\
\hline Constant value & 9.525 & 1.242 & 7.666 & $<0.001$ \\
\hline GAD & 0.251 & 0.019 & 13.515 & $<0.001$ \\
\hline Age & -0.019 & 0.008 & -2.262 & 0.024 \\
\hline Death of relatives due to COVID-19 infection & 1.347 & 0.408 & -3.303 & 0.001 \\
\hline
\end{tabular}

$\mathrm{SE}$ - standard error, $p$ - $p$-value, GAD - generalized anxiety disorder. 
The single most striking observation to emerge from the data comparison was that according to the multivariate linear regression model, $15 \%$ of the death anxiety variance is explained by the variables within the model. Thus, with the increase of each unit of anxiety and death of relatives due to COVID-19, death anxiety increases by 0.251 and 1.347 , respectively. Moreover, the death anxiety score decreases by 0.019 units by the increasing in each year of age (Table 4).

\section{Discussion}

It can be concluded that a good number of participants in this study reported high death anxiety. In addition, parallel to a high anxiety level, a significant increase in death anxiety was observed. Moreover, factors such as younger age and the death of a family member due to COVID-19 were significantly correlated with death anxiety in the participants.

The results of the present study showed that the majority of participants were enjoying an acceptable level of awareness of COVID-19. One of the possible reasons for this finding is proper accessible public education to community dwellers and their follow up on COVID-19. Social mass media can play an important role to alleviate fear and anxiety in the community during the COVID-19 outbreak [4].

The results of the present study showed that about one-fifth of the participants in the study experienced high anxiety. Meanwhile, the results of the study in China showed that $34 \%$ of the general population experienced anxiety during the $\mathrm{CO}$ VID-19 outbreak [8]. The differences in results can be due to the difference between cultural and social construction or even the difference in the severity of COVID-19 in terms of infection and mortality in the studied communities. The results of a study in China showed that approximately $25 \%$ of participants experienced a higher level of anxiety during the COVID-19 outbreak, which is consistent with the results of the present study [19]. Since COVID-19 is highly contagious, the fear of COVID-19 is likely due to its novelty and the uncertainties about how bad the current outbreak might become [4]. In addition, community dwellers may experience depression, fear and anger in the current context of isolation and quarantine. It has been shown that in the absence of interpersonal communication, anxiety disorders are more likely to occur or become exacerbated [20]. Even people without experience of COVID-19 infection are psychologically affected by the widespread COVID-19 disease. A significant increase in fear in the community and a decrease in economic and social activities may have psychological and social consequences [21]. It has been well recognized that exposure to natural and human disasters is associated with a wide range of negative health consequences, including post-traumatic stress disorder, depression and GAD [22]. In the case of experiencing anxiety in society, the experience of excessive disasters likely weakens the sense of security and hope for the future. As a result, the risk of mood and anxiety disorders increases. Other research suggests that stable social and economic stressors may also pose a greater risk in this regard [23].

The results showed that almost half of the participants in the study experienced high death anxiety. Death anxiety has been studied in previous recent outbreaks. For example, the results of a study in Mexico showed that death anxiety, depression and stress were $17 \%, 3 \%$ and $3 \%$, respectively, in the influenza $\mathrm{A} / \mathrm{H} 1 \mathrm{~N} 1$ outbreak [24]. Differences in the results can be justified by stating the time interval between the studies, the difference in the cultural and social status of the communities and the type of disease in the study pandemic. Another possible reason for the higher outbreak of death anxiety in the present study can be the existence of numerous rumors about the consequences of COVID-19. This anxiety may be due to a type of psychological problem called "headline stress disorder", in which there is a high emotional response to news media reports, such as feel- ings of anxiety and stress. Although it is not a medical diagnosis, this can lead to physical and psychological problems [25].

The results showed that the majority of male subjects experience a lower level of death anxiety. This finding is in line with the results of previous studies that found more anxiety in female subjects $[26,27]$. Previous literature supports that GAD is directly related to death anxiety [28]. It supports the results of the study which indicated that death anxiety was significantly associated with a generalized anxiety disorder. Similarly, the results of a study in Saudi Arabia (2020) found that generalized anxiety is significantly related to stress level [29]. Furthermore, the results of the present study showed that death anxiety had a significant inverse relationship with people's age. Similar studies in Iran found that among the Iranian population, death anxiety declines with age $[30,31]$. Based on this result, it can be concluded that with increasing age, people's opinion of death and life after death becomes more realistic, and as a result, they express less fear and anxiety when confronting critical situations, of which death may also be a part (e.g. outbreak of infectious diseases, natural disasters, war, terrorism, etc.).

The results showed that death anxiety is significantly associated with the death of relatives. It can be stated that with the death of the participants' relatives, they showed a more realistic image of the lethality of COVID-19. In fact, they may feel that their life is jeopardized by corona virus infection. They may even reconsider their view of safety and health in the face of the virus and act strictly and obsessively in this regard, which in itself will cause anxiety in people. However, in the present study, there was no significant relationship between relatives and anxiety in individuals. The probable reason for the discrepancy between the results may be due to a high level of awareness about the disease, or the participants in the present study may have used problem-based coping methods [32].

Since the study was limited to subjects with access to the Internet, it was not possible to collect data from other potential subjects. Moreover, it is unfortunate that the study did not include the subjects' details, such as a history of COVID-19 and economic status.

Shahroud County in the Semnan Province is located in the northeast of Iran and has a population of about 218,628 based on the results of the latest census in 2016 [33]. Khosravi et al. (2020) found that COVID-19 was prevalent in Shahroud County [34]. It is predictable that the COVID-19 outbreak imposes a high mental burden on communities, such as fear of death and anxiety among community dwellers all over the world.

\section{Conclusions}

Considering the adverse effects of anxiety on community dwellers' mental health, this is not merely an issue for hospitalized patients. Health care providers at the community level, especially general physician and nurses, are in a good position to recognize anxiety and implement strategies to alleviate it. Moreover, it is suggested that superior managerial organizations, along with mental health associations and professionals, implement empowerment and comprehensive mental support programs for community dwellers.

Acknowledgements. The present study was a result of a research project approved by the research deputy of Shahroud University of Medical Sciences under referral code of 98138 . We would like to express our thankfulness and gratitude to the deputy of Research and Technology and the Center for Health Research and Behavioral Sciences of Shahroud University of Medical Sciences for their contributions for conducting the study.

Source of funding: This work was funded from the authors' own resources.

Conflicts of interest: The authors declare no conflicts of interest. 


\section{References}

1. Duan L, Zhu G. Psychological interventions for people affected by the COVID-19 epidemic. Lancet Psychiatry 2020; 7(4): 300-302.

2. Bao Y, Sun Y, Meng S, et al. 2019-nCoV epidemic: address mental health care to empower society. Lancet 2020; 395(10224): 37-38.

3. Xiang Y-T, Yang Y, Li W, et al. Timely mental health care for the 2019 novel coronavirus outbreak is urgently needed. Lancet Psychiatry 2020; 7(3): 228-229.

4. Asmundson GJ, Taylor S. Coronaphobia: fear and the 2019-nCoV outbreak. J Anxiety Disord 2020; 70: 102196.

5. Hoelterhoff M, Chung MC. Death anxiety and well-being; coping with life-threatening events. Traumatology 2013; 19(4): $280-291$.

6. Menzies RE, Sharpe L, Dar-Nimrod I. The relationship between death anxiety and severity of mental illnesses. Br J Clin Psychol 2019; 58(4): 452-467.

7. Wang C, Pan R, Wan X, et al. Immediate psychological responses and associated factors during the initial stage of the 2019 coronavirus disease (COVID-19) epidemic among the general population in China. Int J Environ Res Public Health 2020; 17(5): 1729.

8. Huang Y, Zhao N. Generalized anxiety disorder, depressive symptoms and sleep quality during COVID-19 epidemic in China: a webbased cross-sectional survey. Psychiatry Res 2020; 288: 112954.

9. Australian Government Department of Health. Coronavirus (COVID-19) 2020 (cited 20.03.2020). Available from URL: https://www. health.gov.au/health-topics/novel-coronavirus-2019-ncov.

10. Gao J, Zheng P, Jia Y, et al. Mental health problems and social media exposure during COVID-19 outbreak. PLoS ONE 2019; 15(4): e0231924.

11. Rosenblatt A, Greenberg J, Solomon S, et al. Evidence for terror management theory: I. The effects of mortality salience on reactions to those who violate or uphold cultural values. J Pers Soc Psychol 1989; 57(4): 681.

12. Overall C. Aging, death, and human longevity: a philosophical inquiry. Berkeley (CA): University of California Press; 2003.

13. Mercês CAMF, Souto JdSS, Zaccaro KRL, et al. Death anxiety: concept analysis and clarification of nursing diagnosis. Int J Nurs Knowl 2019; 31(3): 218-227.

14. Fitri RA, Asih SR, Takwin B. Social curiosity as a way to overcome death anxiety: perspective of terror management theory. Heliyon 2020; 6(3): e03556.

15. Templer DI. The construction and validation of a death anxiety scale. J Gen Psychol 1970; 82(2): 165-177.

16. Rajabi GR, Bohrani M. Item factor analysis of the death anxiety scale. J Psychol 2002; 5(4): 331-344.

17. Spitzer RL, Kroenke K, Williams JB, et al. A brief measure for assessing generalized anxiety disorder: the GAD-7. Arch Intern Med 2006; 166(10): 1092-1097.

18. Naeinian $M$, Shaeiri $M$, Sharif $M$, et al. To study reliability and validity for a brief measure for assessing Generalized Anxiety Disorder (GAD-7). Sci J Clin Psychol Pers 2011; 2(4): 41-50.

19. Cao W, Fang Z, Hou G, et al. The psychological impact of the COVID-19 epidemic on college students in China. Psychiatry Res 2020; 287: 112934.

20. Xiao C. A novel approach of consultation on 2019 novel coronavirus (COVID-19)-related psychological and mental problems: structured letter therapy. Psychiatry Investig 2020; 17(2): 175.

21. Brooks SK, Webster RK, Smith LE, et al. The psychological impact of quarantine and how to reduce it: rapid review of the evidence. Lancet 2020; 395(10227): 912-920.

22. North CS, Pfefferbaum B. Mental health response to community disasters: a systematic review. JAMA 2013; 310(5): 507-518.

23. Lowe SR, McGrath JA, Young MN, et al. Cumulative disaster exposure and mental and physical health symptoms among a large sample of Gulf Coast residents. J Trauma Stress 2019; 32(2): 196-205.

24. Elizarrarás-Rivas J, Vargas-Mendoza JE, Mayoral-García M, et al. Psychological response of family members of patients hospitalised for influenza A/H1N1 in Oaxaca, Mexico. BMC Psychiatry 2010; 10(1): 104.

25. Liu M-Y, Li N, Li WA, et al. Association between psychosocial stress and hypertension: a systematic review and meta-analysis. Neurol Res 2017; 39(6): 573-580.

26. Saleem T, Saleem S. Religiosity and death anxiety: a study of Muslim Dars attendees. J Relig Health 2020; 59(1): 309-317.

27. Dadfar M, Farid AAA, Lester D, et al. Effectiveness of death education program by methods of didactic, experiential, and $8 \mathrm{~A}$ model on the reduction of death distress among nurses. Int J Med Res Health Sci 2016; 5(7): 60-71.

28. Pashak TJ, Oswald SR, Justice MD, et al. You are alive right now: an experimental exploration of the interplay between existential salience, mental health, and death anxiety. Coll Stud J 2017; 51(4): 451-462.

29. Al-Rabiaah A, Temsah M-H, Al-Eyadhy AA, et al. Middle East Respiratory Syndrome-Corona Virus (MERS-CoV) associated stress among medical students at a university teaching hospital in Saudi Arabia. J Infect Public Health 2020; 13(5): 687-691.

30. Sharif SP, Nia HS, Lehto RH, et al. The relationship between spirituality dimensions and death anxiety among Iranian veterans: partial least squares structural equation modeling approach. J Relig Health 2019: 1-16, doi: 10.1007/s10943-019-00931-6.

31. Soleimani MA, Lehto RH, Negarandeh R, et al. Death anxiety and quality of life in Iranian caregivers of patients with cancer. Cancer Nurs 2017; 40(1): 1-10.

32. Song Z, Xu Y, Bao L, et al. From SARS to MERS, thrusting coronaviruses into the spotlight. Viruses 2019; 11(1): 59.

33. Statistical Center of Iran. Selected findings of 2016 national population and housing census (cited 18.09.2020). Available from URL: https://www.amar.org.ir/english/Population-and-Housing-Censuses.

34. Khosravi A, Chaman R, Rohani-Rasaf M, et al. The basic reproduction number and prediction of the epidemic size of the novel coronavirus (COVID-19) in Shahroud, Iran. Epidemiol Infect 2020: 1-21, doi: 10.1017/S0950268820001247.

Tables: 4

Figures: 0

References: 34

Received: 3.10 .2020

Reviewed: 9.10.2020

Accepted: 24.11 .2020
Address for correspondence:

Hossein Ebrahimi, PhD

Center for Health Related Social and Behavioral Sciences Research Shahroud University of Medical Sciences

7th Sq. Shahroud

Iran

Tel.: +982332393811

E-mail: ebrahimi@shmu.ac.ir 